\title{
Integrating indigenous knowledge practices as context and concepts for learning of curriculum science: A methodological exploration
}

\author{
Caleb Mandikonza, University of the Witwatersrand, South Africa
}

\begin{abstract}
Teachers and learners bring tacit as well as explicit knowledge into learning contexts. In the science classroom, learners' tacit knowledge can involve sustainability practices that have been passed down for many generations and have enabled people to survive in their particular environment and derive benefit from it. This study examines an example of such a practice that was observed in a rural community. The study sought to establish whether such a sustainability practice could be incorporated into the formal science teacher training classroom with a view to expanding the teaching and learning of science curriculum concepts. The study was carried out through observation of rural participants as they conducted certain sustainability practices as well as through interviews with the participants. Student teachers preparing for lesson planning and teaching presentations (as part of their peer-teaching activities) engaged with these sustainability practices in a six-phase process. Socio-cultural approaches guided the analysis. The study showed that, through a carefully considered methodological approach, it was possible to use those practices with which learners were familiar in their daily lives - that is, their habitual indigenous knowledge practices (IKPs) - to unpack and explain related scientific concepts from the school science curriculum in the classroom (habitual practices of classroom science) (Bourdieu, 1998). The study illustrated how knowledge of science can be developed from context to concept. The study was only conducted with student teachers in a peer-teaching context, but it would be interesting to investigate how such an approach could be used by student teachers during their teaching practice as well as by teachers who teach at the secondary school level.
\end{abstract}

\section{Introduction}

The quest for quality education has been promoted by UNESCO since the Jomtien Conference (UNESCO, 1990), which called for 'Education for All'. Education quality was understood in terms of meeting everyone's basic needs. This call was followed by the Dakar Education for All Conference (UNESCO, 2000), which focused on enabling improved education practice to facilitate better epistemological access and retention in schools. This focus grew into the commitment to promote more inclusive forms of educational experiences. As education has become more inclusive in terms of numbers, gender and different communities, the concept of quality education has evolved to mean the relevance and effectiveness of what actually happens in classrooms, as proposed by the Incheon Declaration and Framework for Implementing Sustainable Development Goal (SDG) 4 (Magni, 2016).

Classroom experiences are determined by contextual factors. Learners from rural and disadvantaged communities tend to find a poor fit between their home experiences and what they learn at school. Such learners tend not to see the relevance of school curriculum 
knowledge and concepts with respect to their personal and communal lives (Mandikonza, 2007). Accordingly, the call of the Incheon Declaration is to make education more inclusive.

Curriculum knowledge should valorise and integrate learners' prior knowledge that they bring from home, and use aspects of this knowledge as the starting point for enabling learners to understand the scientific concepts described in curriculum-based textbooks. In so doing, the hope is to facilitate epistemological access while simultaneously enhancing the relevance of curriculum concepts in learners' lives. Knowledge that learners bring from home may simply be experiential knowledge in the form of specific practices; however, these practices are also specific to particular communities and can therefore be described as indigenous knowledge practices (IKPs). Indigenous knowledge, according to UNESCO (Magni, 2016), encompasses knowledge and practices that are unique to particular communities, cultures or societies. In addition to practices, these knowledge systems include values, beliefs and world views. These forms of knowing often serve as the ways a community manages their concerns about environmental sustainability and, materialising at the intersectionality of human life, these forms of knowing have been maintained for many generations (Odora Hoppers, 2005). Odora Hoppers (2005) further states that users' knowledge may be either explicit or tacit. Even though indigenous knowledge is mostly specific to particular communities, there are some aspects that are common among diverse communities (Sillitoe, 2006). For example, the process of brewing traditional beer is widespread among diverse communities, with only minor variations.

This article presents an attempt to integrate IKPs concerned with sustainability into the science curriculum as a starting point for assisting pre-service or student teachers at a teacher training college to develop an understanding of scientific concepts.

\section{Background}

As the Zimbabwean economy declined, the government progressively withdrew its support for schools. Conventional resources such as textbooks became very expensive. Laboratory resources became both expensive and unavailable. Schools in rural areas have suffered the most, as learners cannot afford to pay the fees to purchase the needed resources. Only the teacher has the recommended textbook and the learners thus depend on the teacher's knowledge and notes. But all learners taking science have to work through the same national curriculum and sit for the same national examinations. The aim of this study was to enable learners to understand curriculum science concepts in ways that enable them to discover the relevance of these concepts to their lives, and to develop a view of science in the community by building on the sustainability of their IKPs (Agrawal, 1995; Le Grange, 2004). The class of student teachers in this study comprised two cultural groups of students. One group came from Zimbabwe, mostly from a Shona cultural background, while the other group was composed of Namibians, the majority of whom were of the Oshiwambo culture.

Teachers and learners bring tacit as well as explicit and conceptual knowledge into learning contexts. Educators and learners therefore possess indigenous and cognitively located knowledge, knowledge skills and knowledge practices, hereafter referred to as IKPs, which can also be tacit because these include things that they know (knowings) and things that they do 
very proficiently (doings), mostly without conscious thought (Kemmis, Wilkinson, EdwardsGroves, Hardy, Grootenboer \& Bristol, 2014; Mandikonza, 2007). Mudaly and Ismael (2013) recognise the embeddedness of indigenous knowledge in human experiences, the validation of which developed over many years of trial and error through varied learning processes and with the ultimate practical wisdom that is possessed and shared at different levels of society. The educators and learners would have learnt these practices as part of their lived experiences. As such, these lived experiences constitute the context as well as the prior knowledge of practical solutions to daily challenges that learners bring to class (Cole, John-Steiner, Scribner \& Soubeman, 1978). Since some IKPs involve concepts that are considered scientific (Mandikonza, 2007), their integration into school learning would therefore have the potential to engender the contextual relevance of curriculum science concepts as well as a better understanding of the concepts themselves. The IKPs, therefore, constitute what Bourdieu (1998) terms the learners' and educators' 'habitus'. Accordingly, this article reports on an exploration of the potential for using these knowings and doings (habitus) to enhance leaners' understanding of classroom science.

Learners are said to understand concepts when the 'zone of proximal development' (ZPD) shifts (Cole et al., 1978). Engeström and Sannino (2010), citing Davydov (1997), who in turn draws on the dialectical philosopher Illeykov (see below), assert that concepts ascend from the abstract to the concrete. That is to say, learners understand concepts in such ways that they can then generalise from them. Learners begin with aspects of the concepts they can relate to, but when they have fully understood the concepts via more concretely engaged processes, they can then relate to them at an abstract level. Abstract knowledge is, according to Barsalou (1982), context-independent knowledge, while more concrete knowledge is context-dependent.

The purpose of this investigation was to establish how selected IKPs could be used to mediate the understanding of respective and related classroom science concepts in ways that would enable pre-service teachers to understand curriculum concepts more deeply (from the abstract to the concrete) by expanding their ZPD (Cole et al., 1978). The research project was conducted with trainee teachers - also referred to as pre-service teachers or student teachers - during their first year of study, and was undertaken during student teachers' peer-teaching and micro-teaching practical experiences. For students preparing to go on teaching practice, peer-teaching and micro-teaching are preparatory stages in the Methodology component of the training for science teachers. During peer-teaching, a group of four or five student teachers work together to plan what to teach. Each one takes about 15 minutes to present part of a concept to a bigger group of about 15 student teachers.

The intention was to build IKPs into the suit of knowledge practices possessed by student teachers which would influence how they achieved intended lesson outcomes during their teaching practice and maximise their ability to adapt their teaching plans in response to contextual constraints, including the unavailability of conventional science resources in schools (Wertsch, 1991). This study was not focused on the differences between indigenous and western (classroom) science knowledge, but on the potential of working with both knowledge systems in order to build a better understanding of the science concepts in the curriculum upon which learners are examined. 


\section{Theoretical framework}

Socio-cultural approaches - particularly the work of Vygotsky (Cole et al., 1978) - were used as lenses for the analytical process of the study. Socio-cultural theory is built on the premise that learners construct knowledge. This construction is supported by the key features of sociocultural theory, which claim that knowledge is not just transferred to learners; rather, they actively construct knowledge using the knowledge they have gained from a knowledgeable other at various levels, usually a parent or other teachers, including knowledgeable peers. As such, learning emerges out of social interactions with referents in activity. Learning, according to Vygotsky, is the development of higher psychological functions, which he referred to as higher mental functioning (Daniels, 2008). In the literature, these psychological functions are referred to as cognition or cognitive processes.

According to Vygotsky, all learning is mediated (Daniels, 2008). Learning is therefore the outcome of a learner interacting with other people as well as with the tools provided to facilitate the learning process. Such dyadic interactions either involve a knowledgeable other or they occur between peers (Warford, 2010). A learner may interact with physical tools, artefacts or psychological tools while learning with a knowledgeable other such as a teacher (Engeström, 2001). Wertsch (1991:32), citing Vygotsky, states that the introduction of a 'psychological tool alters the entire flow and structure of mental functions. It does this by determining a new instrumental act.' The IKPs in the study represent the psychological tools and their physical artefacts, the use of which was intended to influence student teachers' learning about curriculum science and thus facilitate learning of the subject in school classrooms. Vygotsky's view is that cognitive development occurs once learning has occurred.

Learning takes place at two levels: first on the social level, which involves other people and associated mediatory artefacts (inter-psychological); and, second, at the individual level, where the learner processes and internalises the knowledge (intra-psychological) through a meaning-making or semiotic process (Wertsch, 1991). This means that individuals first experience the world through social processes where language, knowledge and experiences are culturally shared via other learners, adults, mediating tools and artefacts or a teacher. Through the socialisation process, symbols (language and prior concepts) are formed and cognitive development then becomes a process of ordering, patterning and finding connections between the symbols. This enables the development of thought and thought processes, a process Vygotsky calls internalisation. During internalisation, the externally generated and mediated experience is converted into the internal form, with the mediated experience undergoing a complex transformation process in the mind. It can therefore be said that a symbol has an indicative function externally while having a semantic and semiotic function internally. Since people are socialised differently in diverse contexts, people from different cultures are thought to have different thinking tools because they have internalised different external stimuli in their particular context. The student teachers in this study were encouraged to understand the documented practices from the perspective of their own cultural experiences before going on to relate them to the concepts and practices of the school science syllabus. The research design was intended to encourage student teachers to relate to familiar IKPs before relating these to classroom science concepts in a process of 
meaning-making which used IKPs as artefacts to generate meaning in relation to school science curriculum concepts.

Further to this, cognitive development is facilitated when learners interact with each other in the process of learning and while they use new tools. In this regard, the teacher brought some IKPs into the context of learning how to teach science to student teachers, using the school science curriculum in order to introduce activities that have the potential to promote understanding of conventional science concepts. Members of the school community brought baskets for enacting the process of separating chaff from maize. These are physical tools and artefacts. Indigenous knowledge practices also involve non-physical artefacts such as language, which can be verbal or non-verbal. Language as a key meaning-making process was a symbol used in the study - student teachers wrote about the IKPs in their mother tongue and also discussed and demonstrated their understanding and familiarity with the practices with each other in their mother tongue (Hasan, 2004).

The principle of the ZPD describes the process of learning and consequent cognitive development in relation to instruction. It is defined as the difference between the functions that the learner has achieved and can do independently, and what the learner may still achieve given the support of a more knowledgeable other (Cole et al., 1978; Daniels, 2008). Those functions for which the learner needs to or can gain from a knowledgeable other, are not yet fully developed. The ZPD acknowledges that different learners can achieve at different levels. It further acknowledges that different learners need different kinds of support, and different ZPDs will be distributed around a learning environment such as a classroom. To reduce the differences between the ZPDs of individual student teachers during this study, and since the ZPD develops during interactive activity, the researcher and lecturer encouraged student teachers to work collaboratively in small groups. The hope was to promote the use of distributed cognition (Daniels, 2008).

\section{Methodology}

A qualitative approach guided the interpretive case study design (Bassey, 1999; Terre Blanche, Durrheim \& Painter, 2006) and enabled the researcher - through involvement and participation and by focusing on what participants said and did - to learn at first-hand about the social world under investigation. The IKPs under observation were inherent to participants' livelihoods. While working with the student teachers, the researcher collected data on classroom use of IKPs. To this end, the qualitative research process brought the researcher and research participants closer together whilst drawing attention to what ordinarily and routinely happens in educational processes (Yin, 2009). Ultimately, research-focused interactions had the potential to culminate in a greater understanding between educator-researcher and subject-learners, an understanding that could enhance the learning of concepts under investigation and of any other topic in the curriculum.

The study was interpretive because it took cognisance of rural community members' and the students' experiential knowledge whilst studying what they made of these experiences (Terre Blanche et al., 2006). The study probed these people's intergenerational and sustainable ways of knowing (subjective experiences) during the teaching of science to make the learning 
of science contextually relevant (relatable to views of knowledge) whilst looking at ways to promote sustainable living.

The study design had six phases. During the first phase, the researcher explored and recorded IKPs in a rural area whilst among members of that community as they went about their daily lives. The observed practices were recorded by writing down all the details of the proceedings, and some moments in the process were photographed. Members of the rural community were interviewed about each of the observed IKPs in order to get details on how and why they conducted themselves that way. The researcher observed the preparation of harvested grain for storage, which included the pounding, winnowing (kupepeta) and storage of grain; the making of amahewu (an unfermented drink); the treatment of milk (preserving fresh milk for later use and souring); the making of a fire in a traditional hut; and the preparation of the staple maize porridge (sadza/pap). These observations and interviews were rewritten into vignettes and, where possible, illustrations were attached.

During phase two, the vignettes were brought to class, where an elderly woman from the teacher training college community was invited to enact some of the practices, such as separating grain from chaff, making a fire and making mahewu. While the woman did the demonstrations, student teachers were invited to enact the same processes but as they did them at home. After the demonstrations, student teachers read through the provided vignettes and then discussed the documented IKPs in terms of their own experiences at home. Any variations in practice were then added to the vignettes.

During the third phase, student teachers worked in groups of four to conduct a curriculum audit to establish whether the IKPs described in the vignettes and then demonstrated could be related to scientific concepts in the science curriculum (the Zimbabwe Junior Certificate Science (ZJC) Syllabus). The lecturer (the researcher) analysed the syllabus content and identified scientific concepts that related to the documented IKPs. Because the researcher wanted to establish how close the student teachers would get to the identified concepts during their audit, the researcher's analysis of the science concepts was not shown to the student teachers. In the vignettes provided here, the researcher's views are in italics.

In the fourth phase, students prepared lesson plans in which they used the IKPs as alternatives to the recommended and conventional activities. Out of a class of 60 student teachers, three groups chose to work with the vignette on separating different solid substances (grain from chaff) and the related syllabus concepts. Other groups chose other vignettes. This study focuses on the progress of the three groups interested in the solids-separation vignette.

The fifth phase saw student teachers using the prepared lesson plans to teach their colleagues during peer-teaching activities. In phase six, working through focus group discussions, student teachers reflected on and reviewed the mini lessons to determine how suitable the IKP was for developing curriculum science concepts.

From the observations in the field, the IKPs were noted to have emergent structural patterns. The practices were constituted in such a manner that they followed a sequential progression, a process that may have arisen from repeated practice as users were growing up.

This paper presents my views as I observed the sustainability IKPs, which I summarised in narrative form under the subtopics 'What I saw; What I heard; and What I thought' as presented in Insert 1. 
Insert 1. Vignette on researcher observations in the field

\begin{abstract}
Separation of grain from chaff

\section{What I saw}

The homestead in Manesa village which I visited lies on the western side and at the base of the hill slopes of the Mutema mountain range. This mountain range runs from north to south. It was in the early afternoon when I arrived and after the usual greetings the grandmother brought out baskets (tswanda nerusero[C]) with maize grain in a tswanda [C] (deep basket) and threw some grain into the air. She then left to do other chores for about an hour. When she came back she repeated the tossing of grain. She put some maize into the rusero [C] (flat basket) and went on to systematically winnow with her back to the mountain and the basket and hands strategically held in the air at an angle to the body, away from her and at a distance that prevented her from intercepting the air currents. At the same time she kept her eyes, nose and clothes free from the floating chaff. The position of the rusero prevented the chaff from whirling around her; instead it floated away as she winnowed while maize grains fell into the tswanda [C]. I joined her and she taught me how to winnow gently. She teased me because this was a feminine chore and male sons-in-law were supposed to do masculine chores like constructing and repairing granaries as well as repairing livestock kraals. I had to stand in a particular position so that chaff did not go into my eyes. I had to allow a reasonable amount of grain to come out of the rusero $[\mathrm{C}]$ while shaking the rusero $[\mathrm{C}]$ slightly. We did this in turn until all the grain was finished - but I always got a lot of chaff onto my clothes and face.
\end{abstract}

\title{
What I heard
}

When I asked the grandmother why she had tossed grain when she did, she said she that first time she tested the strength of the breeze - early in the afternoon it was too weak. The chaff fell very close to the tswanda $[\mathrm{C}]$. The second time she tested, the breeze was strong enough. Chaff was blown further away from the $t s w a n d a[C]$. She was winnowing her grain to take to the grinding mill on the following day. She noted that dutu rinowanda manheru [C] (breezes are stronger in the evenings). When I asked what would happen in the total absence of wind she took me to the family's threshing platform and showed me heaps of ash. She described these as arising from fires that were made to create mhepo yemukwasha [C]. On a very calm day, she would perform the same process of tossing chaff into the air. Where the chaff falls indicated the direction of the weak breeze. She made a fire at the end of the platform in the direction of the falling chaff. She sang along with the burning fire. The song challenged sons-in-law of the family, whom she named, in turn, to blow a stronger breeze so that they could use the grain to make traditional beer. She said if she calls the name of one who wants traditional beer the most, the breeze will be stronger.

\section{What I thought}

The practice of winnowing observed made use of concepts of winds that descended from the mountains in the evening. Having noticed that the breeze around midday had no particular direction but blew down the hill slopes in the afternoon, I wondered whether these winds got stronger as evening approaches. These observed air movements constitute the ascending and descending winds that are taught under 'Pressure Systems' in Physical Science section of the ZJC and O level syllabuses. The separation of grain from chaff depended on their differential densities of the grain and chaff. The fire that is used on a calm day as she described was to generate stronger winds by convection, another concept in Physical Science. In the syllabus, teachers were expected to illustrate convection currents using the chimney box with a burning candle under one chimney at one end and a smouldering splinter at the other. Separation of grain from chaff does not show details of calculating density but gives practical uses of the idea of density in everyday life. The practice can also be used as a starting point to develop the concept of density. Learners can start from their experiences with density before the theoretical concept is defined or calculated. When teachers start with the indigenous process and try to explain it, they develop the conceptual content from the vantage point of the learner. It will not be the educator bringing knowledge to the class but the educator building on the knowledge of the learner. I also thought about the way people learn in the home context. 
With these observations and reflections, the vignette on the respective practice was then written up.

\title{
Vignette from the field
}

After students had watched the college community elder and had conducted their own demonstrations, they read the respective vignette and added to it as necessary. They then reviewed the ZJC syllabus to establish whether any science curriculum concepts related to the particular IKP. Insert 2 presents the vignette on the separation of grain from chaff (with my reflections on syllabus congruency in italics, which were not shown to student teachers).

Insert 2. Vignette on the separation of grain from chaff

\begin{abstract}
Preparing the grain for storage
Grain is dried on a flat ground that is prepared by smearing the surface with cow dung (storage of food and food crops: pest control and insect repellents-biological sciences) and allowing the surface to dry before any grain heads (maize cobs, sorghum and millet heads) can be spread out to dry. The elderly ladies take note of the prevailing wind direction and they spread the heads to cover this side of the platform. The other side of the platform is reserved for winnowing. The harvested heads are spread on a platform to dry.
\end{abstract}

When perceived dry (elderly women test the dryness by biting on the seeds once in a while using their teeth) (alternative test/ experimental methods), the heads are pounded with sticks to separate chaff from grain. Grain is separated from chaff using air currents (pressure systems-physica/ science) in a process called winnowing. As wind blows, with her back to the mountain and the rusero and hands strategically held in air at an angle to the body, away from her and at a distance that prevented her from disturbing the air currents, at the same time keeping her face free from the floating, the lady starts winnowing. Denser grains drop downwards (density-physical science) whilst air currents carry lighter chaff away. Women do most of this work.

On a calm day the breeze may be too low to carry the chaff. Elderly ladies create a stronger breeze by making a fire (convectional currents-physical science) on one end of the platform. They start by tossing some chaff into the air (density- physical sciences). The direction where the chaff falls shows the direction of the drafts of air, showing that even on a calm day some air will be moving. They then make a fire using some of the chaff or wood at the end of the platform where the wind is blowing. As the fire burns, the ladies toss chaff into the air until a breeze strong enough to be used for winnowing is blowing, meanwhile singing and ululating. Their songs encourage their son-in-laws, naming them in turn to bring some wind. This breeze is called mhepo yemukwasha (son-in-law's breeze). The traditional belief is that the son-in-law who wants the mother-in-law to brew beer for him using the grain that has been winnowed generates the breeze. To continue winnowing they continue adding chaff to the fire. The fire therefore makes a weak breeze blow stronger.

Other techniques employed to separate grain from chaff include sifting (separating substances of different densities-physical science). When sifting the grain is tossed up and down and is shaken side to side until the grains separate from the chaff. Unwanted substances such as stones that have the same weight as the grain seed are picked up singly by hand (separating visibly different solid substances/solld objects of the same density-physical science). This is usually the last stage of the separation process before the grain is poured into a container for storage.

Activity

Now that you have observed acting out on how these processes are done;

1. What do you call this process in your own language and do you do it differently in your community?

2. Make annotated drawings to show how the same process is done in your community.

3. Which of the two, traditional and modern, do you prefer to use and what are your reasons for that choice?

4. On which syllabus (ZJC or " $\mathrm{O}$ "-level) and which syllabus topic (s) can you use this module for science teaching? 
Students discussed these guiding questions in focus groups of ten students. Table 1 presents one of the focus groups' responses.

Table 1. Transcriptions of student discussions responses on making sense of indigenous technologies

\begin{tabular}{|c|c|}
\hline Categories & Responses \\
\hline \multirow[t]{5}{*}{ i. } & Cultural Preference \\
\hline & $\begin{array}{l}\text { Modern- faster, not dependent on weather, no air pollution, need smaller space, requires } \\
\text { a few resources, less disappointment due to bad weather conditions }\end{array}$ \\
\hline & Traditional-separates unwanted (sand, cobs) materials from useful material (Mahangu) \\
\hline & $\begin{array}{l}\text { Modern- save time, less effort, cheaper in terms of labour, can separate large quantities } \\
\text { of grain in the short period of time }\end{array}$ \\
\hline & $\begin{array}{l}\text { Traditional- flour from pure grains, no chemicals added, it is cheap and easily prepared, to } \\
\text { keep our cultural ways of preparing food alive }\end{array}$ \\
\hline \multirow[t]{6}{*}{ ii. } & Relevance to curriculum \\
\hline & Mixing and separation, variation (ZJC) \\
\hline & ZCC \& O-level- convectional currents, mixing and separating \\
\hline & Separation of mixtures \\
\hline & Mixing and separating the substances \\
\hline & On ZJC syllabus \\
\hline \multirow[t]{11}{*}{ iii. } & Cultural similarities and differences \\
\hline & Similarities \\
\hline & Same choice of large seed \\
\hline & Same winnowing and threshing \\
\hline & Done in the same way-beating with sticks \\
\hline & Differences \\
\hline & $\begin{array}{l}\text { Shona people can use cattle to walk over the grain on a rock instead of threshing with } \\
\text { sticks }\end{array}$ \\
\hline & $\begin{array}{l}\text { Storage in clay pot and wood ash added to seed, seed + ash also stored in a conical basket } \\
\text { (okaanda(o)) made from bitter bush (omzimba+omusati)-okaanda plastered with anthill } \\
\text { soil and top sealed with clay soil. }\end{array}$ \\
\hline & Grain pounded to powder with mortar and pestle, not ground \\
\hline & $\begin{array}{l}\text { When making sour milk (Omethe) place calabash in sunshine for } 6 \text { hrs. Shake calabash } \\
\text { vigorously until cream is isolated- cream for cooking and adornment. At times a special } \\
\text { root is added to fresh milk to speed up fermentation process. }\end{array}$ \\
\hline & $\begin{array}{l}\text { Making of ontaku, a traditional drink mainly meant for children. Mahangu and sorghum } \\
\text { flour are added to boiled water are stirred until well mixed.Mixture is cooled. Mixture is } \\
\text { diluted with cold water as the cooling continues until a point where taste of the mixture } \\
\text { still remains. Leave to settle for a few hours or overnight, mix with ready to drink ontaku } \\
\text { before drinking. } \\
\text { Making Omalovu- a non-alcoholic drink. Mixture of sorghum/millet flour with cold water } \\
\text { is allowed to settle. Decant out the water and boil the remnants until the foam produced } \\
\text { disappears. Remove pot from heat. Pour decanted water into filter sack and pour boiled } \\
\text { mixture over it. Keep adding water until filtrate becomes tasteless. Put filtrate in a clay } \\
\text { pot and add millet flour after the filtrate has cooled down. Let filtrate settle for } 12 \mathrm{hrs} \text { and } \\
\text { add a little ontaku or omalovu before consuming. }\end{array}$ \\
\hline \multirow[t]{2}{*}{ iv. } & Role of Language \\
\hline & $\begin{array}{l}\text { Reverting to vernacular throughout the discussions and presentations, drawings made on } \\
\text { the board and in group responses to enhance understanding, reference to vernacular } \\
\text { when giving presentations- students first converse in mother tongue before translating } \\
\text { into English, illustrations on Oshiwambo processing of sour milk + storage structures }\end{array}$ \\
\hline & \\
\hline
\end{tabular}


Following this discussion, student teachers went on to design lesson plans to teach science curriculum topics using the vignettes and demonstrated IKPs. Table 2 shows an overview of the analysis of the structure of the lesson plans made by student teachers in preparation for peerteaching. The observers were the student teachers - the 'pupils' - being taught ZJC science concepts, hence the reference to pupils in the lesson plans.

Table 2. Record of detailed lesson plan structure analysis

\begin{tabular}{|c|c|c|c|}
\hline & Group A & Group B & Group C \\
\hline $\begin{array}{l}\text { Lesson } \\
\text { Objectives } \\
\text { stated }\end{array}$ & $\begin{array}{l}\text { Define separation. } \\
\text { Identify methods used } \\
\text { to separate objects of } \\
\text { different densities; } \\
\text { they must also be able } \\
\text { to show the process }\end{array}$ & $\begin{array}{l}\text { Define separation; distinguish three } \\
\text { types of separating methods which } \\
\text { depend on density particle } \\
\text { size(winnowing, sieving, hand picking); } \\
\text { describe each of the described } \\
\text { methods }\end{array}$ & $\begin{array}{l}\text {-identify methods of separating and } \\
\text { mixing; describe each of the methods } \\
\text { used; show how method is applied }\end{array}$ \\
\hline $\begin{array}{l}\text { Content } \\
\text { shown }\end{array}$ & $\begin{array}{l}\text {-separation of objects } \\
\text { of different densities; } \\
\text { processes separating } \\
\text { solid mixtures- } \\
\text { winnowing, sieving, } \\
\text { hand picking }\end{array}$ & $\begin{array}{l}\text { Mixtures } \\
\text {-homogeneous mixtures } \\
\text {; heterogeneous mixtures; impurities } \\
\text { in mixtures } \\
\text { winnowing; density -maize and chaff } \\
\text {-sieving; handpicking }\end{array}$ & $\begin{array}{l}\text {-different methods of separating; } \\
\text { sifting and picking as methods of } \\
\text { separating objects of different } \\
\text { densities; winnowing as method of } \\
\text { separating solids of different } \\
\text { densities }\end{array}$ \\
\hline $\begin{array}{l}\text { Activities } \\
\text { planned }\end{array}$ & $\begin{array}{l}\text { - teacher asks learners } \\
\text { on general knowledge } \\
\text { and pupils respond by } \\
\text { defining separation; } \\
\text { teacher explains the } \\
\text { processes winnowing, } \\
\text { hand picking, sieving, } \\
\text { pupils listen attentively }\end{array}$ & $\begin{array}{l}\text { - teacher asks pupils to define mixture } \\
\text { and give examples of mixtures, } \\
\text { teacher gives definition of a mixture- a } \\
\text { physical combination of two or more } \\
\text { pure substances in which each } \\
\text { substance retains its own chemical } \\
\text { identity, teacher introduces the topic } \\
\text { of separation, teacher asks pupils why } \\
\text { separating mixtures or substances, } \\
\text { pupils listen attentively and respond } \\
\text { to teacher's questions. } \\
\text { Tr. writes methods of separating } \\
\text { heterogeneous mixtures, explains } \\
\text { winnowing and demonstrates } \\
\text { winnowing, asks pupils to report their } \\
\text { observations, explains sieving, } \\
\text { demonstrates sieving and asks } \\
\text { questions on hand picking }\end{array}$ & $\begin{array}{l}\text {-teacher asks questions such as; what } \\
\text { is sifting, winnowing and hand } \\
\text { picking? Gives more detail on how } \\
\text { these methods are used, ask pupils to } \\
\text { come upfront to demonstrate the } \\
\text { sifting and handpicking, ask pupils to } \\
\text { assist in the demonstration, ask } \\
\text { pupils to go outside, demonstrate } \\
\text { winnowing, ask pupils to assist in the } \\
\text { demonstration/ process, } \\
\text { Pupils observe, ask questions, } \\
\text { respond to questions }\end{array}$ \\
\hline $\begin{array}{l}\text { Use of } \\
\text { LSM } \\
\text { shown }\end{array}$ & $\begin{array}{l}\text { - Focus on Science } 1 \\
\text { page } 26\end{array}$ & $\begin{array}{l}\text {-source of material-handout by Mr. } \\
\text { Mandikonza }\end{array}$ & -none \\
\hline
\end{tabular}

During the peer-teaching, the other student teachers were participant observers. Their observations and ensuing discussions on the appropriateness of the IKPs were guided by the following questions.

1. What were the objectives of the lesson?

2. Which scientific concepts/content were illustrated in the lesson?

3. Does the lesson delivered clearly bring out the concepts intended? How could the detailed lesson plan be improved on?

4. Are there any other scientific concepts that you think could be taught using the same indigenous practices?

5. What are the advantages of using these community-based activities in teaching science over more conventional teaching approaches? 
6. In your thinking, how do such activities impact on learner understanding of separating solid-solid mixtures using density and what are your reasons for saying this?

7. What constraints did you encounter when preparing for these activities, and are there any other constraints you might come across when preparing for such lessons?

Students then sat in focus discussion groups to respond to the questions. Their responses were carefully recorded and then shared with the whole class. Table 3 shows some of the focus group reflections on the lessons demonstrated. Observing students were able to relate the concepts they had been taught to the science curriculum concepts outlined in the syllabus. The responses were categorised using the discussion questions. These questions emerged out of the attempt to establish the efficacy of using an IKP to teach concepts in the science curriculum.

Table 3. Focus group responses to guiding questions on use of indigenous knowledge practices

\begin{tabular}{|c|c|}
\hline Categories & Responses \\
\hline \multirow[t]{2}{*}{ Scientific concepts shown } & -Mixing and separation \\
\hline & -Separation of solids of different density, same density \\
\hline $\begin{array}{l}\text { Topics intended brought } \\
\text { out }\end{array}$ & - Yes, intended concepts were clearly illustrated \\
\hline \multirow[t]{2}{*}{$\begin{array}{l}\text { Possible improvements to } \\
\text { lesson }\end{array}$} & $\begin{array}{l}\text {-It must be improved on the trs and learners activities by making it more child- } \\
\text { centred, letting the pupils to demonstrate what they know. } \\
\text { - can add other activities to separate objects of different densities, like } \\
\text { separating beans and rice from chaff by immersing in water }\end{array}$ \\
\hline & -Can be improved by including other concepts, eg solids of the same density \\
\hline \multirow[t]{3}{*}{$\begin{array}{l}\text { Impact on understanding } \\
\text { of science concepts }\end{array}$} & $\begin{array}{l}\text { - Pupils will understand the concept better because they feel the phenomenon } \\
\text { of what happening } \\
\text { Help pupil recognise easily }\end{array}$ \\
\hline & It can go beyond what they know before \\
\hline & $\begin{array}{l}\text { It makes them to understand because they use and see this process regularly } \\
\text { at the community when their parents even themselves are winnowing maize }\end{array}$ \\
\hline \multirow{8}{*}{$\begin{array}{l}\text { Advantages of } \\
\text { community based } \\
\text { activities }\end{array}$} & $\begin{array}{l}\text {-Availability of materials, easy to understand, relate to everyday activities that } \\
\text { the pupils understand more }\end{array}$ \\
\hline & -Yes it will improve learners' thinking capacity \\
\hline & - This encourages females to do their sciences more \\
\hline & -For pupils to understand and appreciate the community based activities \\
\hline & - pupils can practice it at home \\
\hline & - no laboratory is required \\
\hline & $\begin{array}{l}\text { - community members may recognise more with what is happening in class, i.e. } \\
\text { bringing their materials to class may make them more supportive of teaching } \\
\text { and learning of their children }\end{array}$ \\
\hline & $\begin{array}{l}\text {-other subjects may from science and invite members of the community more } \\
\text { in their lessons }\end{array}$ \\
\hline
\end{tabular}




\begin{tabular}{|l|l|}
\hline $\begin{array}{l}\text { Disadvantages of } \\
\text { community-based } \\
\text { activities }\end{array}$ & $\begin{array}{l}\text { - if teacher's scientific background is based on the text book the tr may not see } \\
\text { usefulness of these practices in classroom learning }\end{array}$ \\
\hline & -unfavourable weather conditions such as absence of wind may affect display \\
\hline & $\begin{array}{l}\text { - spoken language may be a barrier or non-Shona speakers, who may not } \\
\text { accurately describe the processes involved since some terms are difficult to } \\
\text { translate }\end{array}$ \\
\hline $\begin{array}{l}\text {-school administration may not think that that a teacher is doing his/ her job } \\
\text { well if a community member comes to class to demonstrate }\end{array}$ \\
\hline & - parents not involved may not see these activities as necessary for learning \\
\hline & $\begin{array}{l}\text { - learners may think that the teacher is wasting their time as thy are taught by } \\
\text { a community member in vernacular, as initially did the student teachers }\end{array}$ \\
\hline $\begin{array}{l}\text { - Non-Shona speaking students may meet problems trying to identify parents } \\
\text { who can lead these activities }\end{array}$ \\
\hline $\begin{array}{l}\text {-ln some communities in Shiwambo culture men use shovels instead of baskets } \\
\text { and may not find it easy to use baskets when demonstrating such activities. }\end{array}$ \\
\hline
\end{tabular}

These results were then used to discern the findings of the study, as discussed in the next section.

\section{Discussion on the findings}

The study shows that the IKPs under review are constituted of science concepts and principles as well as sustainability principles. The winnowing process is associated with the conventional scientific principle of density; density is used to separate grain from chaff. However, the principle does not work in the absence of strong breezes or wind. Therefore, scientifically, the separation of grain from chaff is conducted in relation to the movement of wind.Wind movement is a relational experience in that it occurs during specific times of the day and can be explained in terms of pressure patterns. Wind movement can occur in relation to local-level convectional currents such as when a fire is set up at one end of the winnowing platform, or at a wider level such as when downhill breezes happen naturally during the evening. People have therefore been able to live sustainable lives by observing patterns of nature over long periods of time and then making use of them. In order to make use of these patterns, such as wind movement patterns, people have developed the appropriate skills. The ability to expertly engage in the process of winnowing is one practice that was developed in relation to wind movement. In some Oshiwambo communities in Namibia, it is the men who do the winnowing, using shovels. As they toss the grain and chaff from one place to another, wind blows away the light chaff to leave the grain. The student teachers knew how to perform these practices very well, as demonstrated by the ladies who enacted them and who seemed to enjoy showing the class what they were capable of. The study showed that it was possible to open up thinking about certain scientific concepts in classroom science (habitual practices of classroom science) (Bourdieu, 1998) through a carefully considered methodological approach using what students knew and were able to perform very well in their everyday lives, namely, their indigenous knowledge practices (indigenous habitual practices).

After observing rural community members, the researcher asked if he could try out the process of winnowing himself. Even though he was not very successful and ended up with chaff on his face, he nevertheless learnt how to handle the basket, how much of the mixture of seed and chaff he should allow to drop at a time and how to position himself in relation to the 
wind direction. This process involved a knowledgeable other, the older member of the family. Since IKPs are generally performative in nature, there is usually a knowledgeable other who engages the learner in an apprenticeship process. However, some practices are limited at times to a specific gender. Cultural issues are likely to become relevant when working with IKPs, and teachers will have to be careful to choose non gender-specific practices. While the college elder was demonstrating, the female students felt comfortable when doing the activity, whereas the male students were reluctant to participate in what they saw as a female chore. Male student teachers could therefore be excluded from some forms of participation.

The demonstration by the college community member was one way of showing the role of a knowledgeable other. She knew how to demonstrate the practice for the student teachers, some of whom had not done it before but still tried it out. The student teachers who were already proficient at the process helped those who were not so skilled.

The study design entailed students working in teams to make sense of the IKP described in the vignette during a review of the syllabus and to then plan lessons with relevant IKPs. Each student chose a section of the lesson plan and presented a 15-minute section of the planned lesson that illustrated the use of an IKP. In the section that they taught, they were to show an aspect of indigenous knowledge and how it linked to science curriculum content specified in the syllabus. Student teachers supported each other at each phase of the study, but also had to each teach part of the lesson back to their peers (Warford, 2010). This process illustrates the strength of the students working at a social level in order to build individual understanding and confidence on lesson delivery (John-Steiner \& Mahn, 1996). To this end, using IKPs to teach science concepts among teachers illustrated the movement from the social to the individual levels (Fernyhough, 2008). It cannot be assumed that student teachers had the same knowledge and expertise with respect to the IKPs brought to class. This was evident when male students refused to take part in the female chore of winnowing. There were also minor cultural differences in the practices, as in some Oshiwambo communities where males used shovels to toss grain into the air, but with the same result. This is an example of distributed cognition. Educators need to take note of distributed cognition and ensure that learners are at the same starting point, as provided for by the textual vignette, before introducing the next task. The syllabus review process would have been different had students not been given the chance to share their home experiences of the demonstrated practices.

The vignettes written up in the field were used as reading and reflective material to guide students to make sense of the IKPs. Student teachers were able to relate their own practices at home with the ones described in the vignettes. Vignettes were therefore used as mediation tools or artefacts to stimulate thinking about practices in their own culture while enhancing meaning-making on the relationship between the content of the vignettes and the content of the science curriculum. The IKPs described in the vignettes were symbolic artefacts or psychological tools that were brought to the class. Physical artefacts included the winnowing equipment that was brought by the college community elder. The equipment enabled student teachers to act out the practices while following the vignette descriptions.

The ZPD in this study was determined in terms of what student teachers knew about IKPs at home and how they were able to use these in planning and executing meaningful lessons. 
Student teachers came to school with knowledge of certain IKPs, with some being able to conduct them expertly. They however had not been involved in the active process of analysing the science curriculum in terms of the IKPs as a starting point for teaching science concepts from the curriculum. The vignettes, demonstrations, the syllabus review and the collaboration around planning and peer-teaching were processes that were used to scaffold student teachers' experiences with IKPs in the classroom.

\section{Conclusions}

The study illustrates how knowledge of science can be developed from context to concept and, further, to expansive concept development by introducing certain IKPs that were then linked to curriculum concepts related to the separation of solid-solid mixtures. Engeström and Sannino's (2010) view of raising learners' understanding from concrete to abstract was illustrated by starting off with practices that students engage in as part of their daily experiences and then extending these to the more abstract conceptual and conventional science concepts involved in the separation of solids in a mixture as they are covered in the curriculum. According to Illyenkov (in Lotz, 2019), science knowledge is abstracted in language (emerging from historical socio-material interactions) until it is experienced and practised in a new setting. Once experienced and practised, it can then be understood as a concrete concept which can then be further abstracted or generalised in more meaningful ways, hence Illyenkov's insight that concepts are formed 'in spiralling abstract and concrete moments of thought in our activity in the material world' (Lotz, 2019:11). Accordingly, the separation of solids is an abstract notion in the language that describes separating mixtures. The practice and process of separating grain from chaff provided a material example and experience of the process of separating solids. It is after experiencing the process of separating grain from chaff that student teachers could develop a more concrete concept of the separation of mixtures. This new understanding is the more meaningful requirement of the school science curriculum, where learners are expected to show their understanding of separating various forms of mixtures. Through the concrete experience, students were better able to access more abstract science concepts and to relate them to other such science concepts in a spiralling and relational way.Via this spiralling and relational process of abstract-concrete encounters, students could relate the process of separation to such notions as density, size and the characteristics of individual constituents of mixtures. The approach used in this study points to the quality education demanded in various international agreements on education, including SDG 4. This is education in which learners can recognise and relate to the knowledge being taught, which is a positive step towards engendering the relevance of education. In so doing, science teaching is not divorced from society, and contributes towards the development of science in society as well as science for society.

The study pointed to the potential of IKPs that involve sustainability for expanding the teaching of curriculum science concepts and, more specifically, for peer-teaching activities in a teacher training college context. The method of starting off with observations in the field and documenting IKPs before sharing them with student teachers seemed to facilitate 
better understanding of the practices. The use of mediating tools such as written materials that in themselves mediated understanding of the practices (which was consolidated by giving student teachers an opportunity to enact the practices using physical tools) seemed to enhance understanding of the practices, which were then used to review the relationship between these practices and syllabus concepts. Once the relationship with syllabus concepts was established, it was much easier for student teachers to design lesson plans that integrated the two forms of knowledge. The study was only conducted with student teachers at teacher training college who demonstrated this potential, but it would be interesting to investigate how such an approach could be used by student teachers during teaching practice as well as by teachers working in schools with secondary school learners.

The study demonstrated elements of catalytic validity (Lather, 1986) as student teachers show interest and enjoyment during the process of teaching science concepts from the viewpoint of IKPs. It is hoped that this positive attitude towards using IKPs in the teaching of science concepts will be carried through into their science classrooms with actual learners.

\section{Notes on the contributor}

\section{Mandikonza, Caleb | School of Education, University of the Witwatersrand, South Africa ORCID: 000-0002-5530-0655 | caleb.mandikonza@wits.ac.za}

Dr Caleb Mandikonza's research interests lie in pre-service science teacher development, teacher academic professional development in the fields of environment and sustainability education, and in indigenous knowledge practices, which he views as providing the backbone of knowledge-skills when conventional classroom knowledge is first encountered.

\section{References}

Agrawal, A. (1995). Dismantling the divide between indigenous and scientific knowledge. Development and Change, 26(3), 413-439.

Barsalou, L.W. (1982). Context-independent and context-dependent information in concepts Memory \& Cognition, 10(1), 82-93.

Bassey, M. (1999). Case study research in educational settings. Buckingham: Open University Press. Bourdieu, P. (1998). Practical reason: On the theory of action. Cambridge: Polity Press.

Cole, M., John-Steiner, V., Scribner, S. \& Souberman, E. (Eds). (1978). Mind in society: The development of higher psychological processes. L.S. Vygotsky. Cambridge, MA: Harvard University Press.

Daniels, H. (2008). Vygotsky and research. London: Routledge.

Engeström, Y. (2001). Expansive learning at work: Toward an activity theoretical reconceptualization. Journal of Education and Work, 14(1), 133-156.

Engeström, Y. \& Sannino, A. (2010). Studies of expansive learning: Foundations, findings and future challenges. Educational Research Review (2010). DOI 10.1016/j.edurev.2009.12.002

Fernyhough, C. (2008). Getting Vygotsky about theory of mind: Mediation, dialogue and the development of social understanding. Development Review, 28, 225-262. 
Hasan, R. (2004). The world in words: Semiotic mediation, tenor and ideology. In G. Williams \& A. Lukin (Eds), The development of language: Functional perspectives on species and individuals (pp. 138-181). London: Continuum.

John-Steiner, V. \& Mahn, H. (1996). Sociocultural approaches to learning and development: A Vygotskian framework. Education Psychologist, 31(3/4), 191-206.

Kemmis, S., Wilkinson, J., Edwards-Groves, C., Hardy, I., Grootenboer, P. \& Bristol, L. (2014). Changing practices, changing education. Singapore: Springer Science and Business Media.

Lather, P. (1986). Issues of validity in openly ideological research: Between a rock and a soft place. Interchange, 17(4), 63-84.

Le Grange, L. (2004). Western science and indigenous knowledge: Competing perspectives or complementary frameworks? SAJHE, 18(3), 82-91.

Lotz, C. (2019). Finding Evald Ilenkoz: How a soviet philosopher who stood up for dialectics continues to inspire. UK: Real Democracy Movement.

Magni, G. (2016). Education for people and planet: Creating sustainable futures for all. Background paper prepared for the 2016 Global Education Monitoring Report. Paris: UNESCO. http://unesdoc.unesco.org/images/0024/002456/245623E.pdf

Mandikonza, C. (2007). Relating indigenous knowledge practices and science concepts: An exploratory case study in a secondary school teacher-training programme. Unpublished Master's Thesis, Department of Education, Rhodes University, South Africa.

Mudaly, R. \& Ismail, R. (2013). Teacher learning through tapping into indigenous knowledge systems in the science classroom. Altemation, 20(1), 178-202.

Odora Hoppers, C. (2005). Culture, indigenous knowledge and the role of the university. Centre for Education and Policy Development Occasional Paper No. 5. Johannesburg: CEPD.

Sillitoe, P. (2006). Introduction: Indigenous knowledge in development. Anthropology in Action, 13(3), 1-12. DOI 10.3167/aia.2006.130302

Terre Blanche, M., Durrheim, K. \& Painter, D. (Eds). (2006). Research in practice: Applied methods for the social sciences. Cape Town: University of Cape Town Press.

UNESCO (United Nations Educational, Cultural and Scientific Organization). (1990). Meeting basic learning needs: A vision for the 1990s. Jomtiem Declaration 1990: World Declaration on Education for All, Jomtien, Thailand, 5-9 March 1990.

UNESCO. (2000). World Education Forum final report. Dakar, Senegal, 26-28 April 2000.

Warford, M.K. (2010). The zone of proximal teacher development. Teaching and Teacher Education, 27, 252-258.

Wertsch, J.V. (1991). Voices of the mind: A sociocultural approach to mediated action. Cambridge, MA: Harvard University Press.

Yin, R.K. (2009). Case study research: Design and methods. London: Sage. 